Detection of aerosolized biological agents by immunoassay followed by autonomous PCR confirmation

John M. Dzenitis, Benjamin J. Hindson, Mary T. McBride, Anthony J. Makarewicz, Bruce D. Henderer, Ujwal S. Sathyam, Sally M. Smith, Dora M. Gutierrez, Thomas R. Metz, Kodumudi S. Venkateswaran, Billy W. Colston, Stephen W. Farrow

February 13, 2004 
This document was prepared as an account of work sponsored by an agency of the United States Government. Neither the United States Government nor the University of California nor any of their employees, makes any warranty, express or implied, or assumes any legal liability or responsibility for the accuracy, completeness, or usefulness of any information, apparatus, product, or process disclosed, or represents that its use would not infringe privately owned rights. Reference herein to any specific commercial product, process, or service by trade name, trademark, manufacturer, or otherwise, does not necessarily constitute or imply its endorsement, recommendation, or favoring by the United States Government or the University of California. The views and opinions of authors expressed herein do not necessarily state or reflect those of the United States Government or the University of California, and shall not be used for advertising or product endorsement purposes.

This work was performed under the auspices of the U.S. Department of Energy by University of California, Lawrence Livermore National Laboratory under Contract W-7405-Eng-48. 


\title{
APDS
}

\section{Detection of aerosolized biological agents by immunoassay followed by autonomous PCR confirmation}

\author{
(Summary of Autonomous Pathogen Detection System \\ aerosol chamber testing conducted September 2003 \\ at the West Desert Test Center, Dugway Proving Grounds)
}

December 2003

Principle Investigator:

John M. Dzenitis, 925-422-6695, john.m.dzenitis@1lnl.gov

Co-Investigators:

Benjamin J. Hindson, Mary T. McBride, Anthony J. Makarewicz, Bruce D. Henderer, Ujwal S. Sathyam, Sally M. Smith, Dora M. Gutierrez, Thomas R. Metz, Kodumudi S. Venkateswaran, Billy W. Colston (LLNL), and Stephen W. Farrow (DPG).

This work was performed under the auspices of the U. S. Department of Energy by the University of California, Lawrence Livermore National Laboratory under Contract No. W-7405Eng-48. 


\section{Executive summary}

An Autonomous Pathogen Detection System (APDS) unit is an automated, podium-sized system that monitors the air for all three biological threat agents (bacteria, viruses, and toxins). The system has been developed under the auspices of the U. S. Department of Energy and Department of Homeland Security by the University of California, Lawrence Livermore National Laboratory (LLNL) to protect people in critical or high-traffic facilities and at special events. The system performs continuous aerosol collection, sample preparation, and multiplexed biological tests using advanced immunoassays as the primary screen. Over ten agents are assayed at once, and results are reported hourly. R\&D work this year focused on incorporating polymerase chain-reaction (PCR) techniques for detecting DNA as confirmation of immunoassay positives.

The primary objective of the Dugway testing was to demonstrate the APDS with immunoassay identification and PCR confirmation of bacteria. A secondary objective was to demonstrate immunoassay identification of a protein toxoid (denatured toxin) aerosol release. A total of 12 agent trials were conducted over 14 days of testing, for a total of four work weeks at Dugway.

Both testing objectives were achieved with multiple releases and clear identifications. The APDS was shown to be effective for identifying aerosolized Bacillus anthracis, Yersinia pestis, Bacillus globigii, and botulinum toxoid.

The two areas for improvement were operational as opposed to hardware-related. The first was slowing the PCR thermal cycling to achieve stronger signals, which was demonstrated during the later phases of testing. The second area is to improve the parameters for autonomous PCR triggering; this is one of the focuses of the upcoming year's work. 


\section{Table of contents}

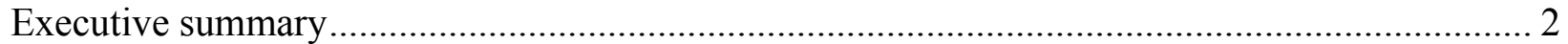

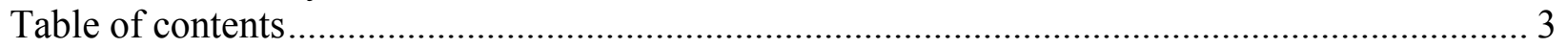

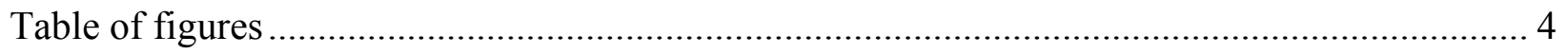

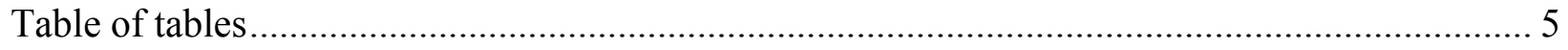

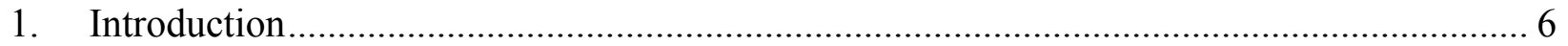

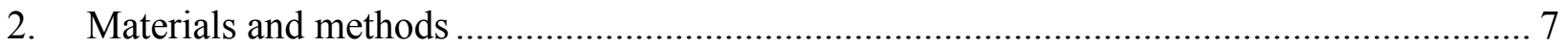

2.1. The Autonomous Pathogen Detection System ......................................................... 7

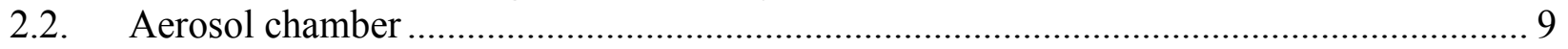

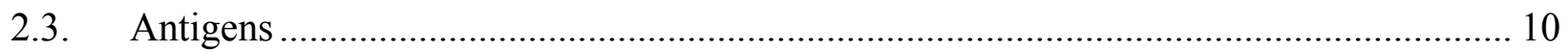

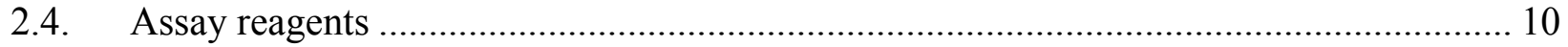

2.5. Bench-top QC and verification assays ............................................................. 11

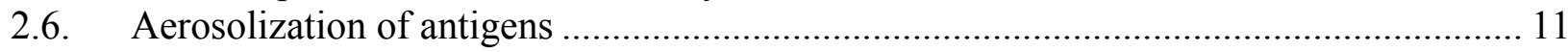

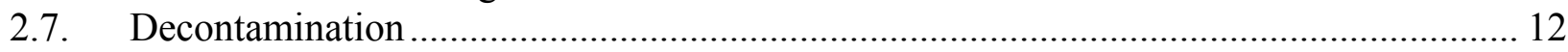

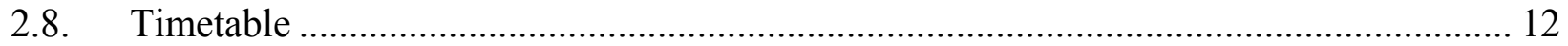

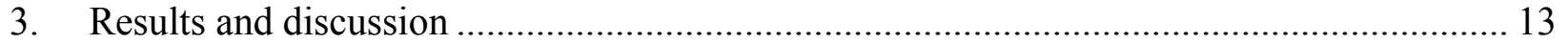

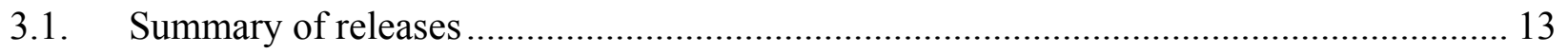

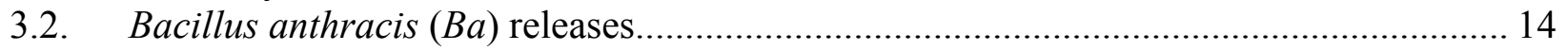

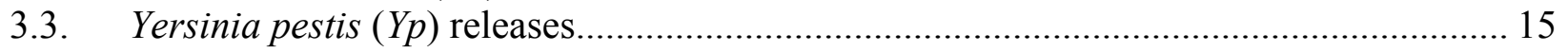

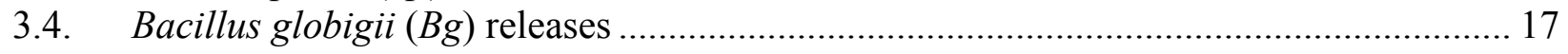

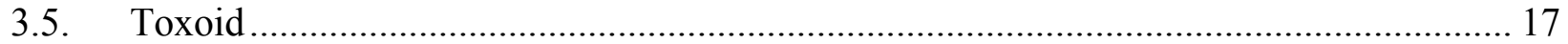

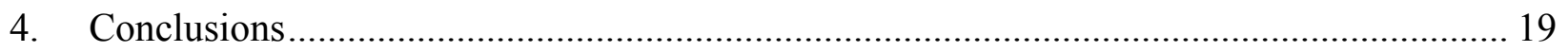

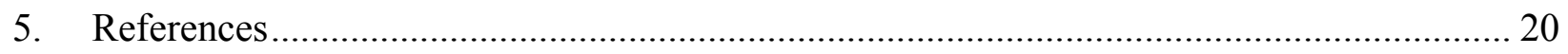




\section{Table of figures}

Figure 1: Process flow diagram of environmental monitoring with the current APDS including PCR confirmation.

Figure 2: The APDS in short field tests in the Albuquerque airport (left panel) and Washington DC subway (right panel).

Figure 3: Photographs of the APDS at the ASEC; most of the system was outside of the camber in the control area (left panel), but the aerosol collector was inside the chamber on a table (visible through the window at the center of the right panel).

Figure 4: Results of Trial 3 showing detection and identification of a $B a$ release using a multiplex immunoassay (left panel) followed by strong PCR confirmation (right panel), as described in the text.

Figure 5: Results of Trial 9 showing detection and identification of a $\mathrm{Ba}$ release using a multiplex immunoassay (left) followed by DNA purification and strong PCR confirmation (right), with a negative sample (blank) for reference.

Figure 6: Results of Trial 4 showing multiplexed immunoassay detection and identification of a $Y p$ release (left), followed by weak PCR confirmation (right). After this experiment the PCR thermal protocol was changed and better results were obtained (Figure 7).

Figure 7: Results of Trial 10 and 11 showing detection and identification of a $Y p$ release using a multiplex immunoassay (left panel) followed by strong PCR confirmation (right panel)... 16

Figure 8: Results of Trial 2 showing detection and identification of a $\mathrm{Bg}$ release using a multiplex immunoassay (left panel) followed by strong PCR confirmation (right panel).. 17

Figure 9: Immunoassay results following aerosolization of botulinum toxoid. ........................ 18 


\section{Table of tables}

Table 1: System test timetable.

12

Table 2: Summary of release and detection results. .

14 


\section{Introduction}

An Autonomous Pathogen Detection System (APDS) unit is an automated, podium-sized system that monitors the air for all three biological threat agents (bacteria, viruses, and toxins). The system has been developed under the auspices of the U. S. Department of Energy by the University of California, Lawrence Livermore National Laboratory (LLNL) to protect people in critical or high-traffic facilities and at special events. (Support from the DOE was transferred to the Department of Homeland Security with its formation in FY03.) The system performs continuous aerosol collection, sample preparation, and multiplexed biological tests using advanced immunoassays as the primary screen. Over ten agents are assayed at once, and results are reported hourly. R\&D work this year focused on incorporating polymerase chain-reaction (PCR) techniques for detecting DNA as confirmation of immunoassay positives.

The primary objective of the Dugway testing was to demonstrate the APDS with immunoassay identification and PCR confirmation of bacteria. A secondary objective was to demonstrate immunoassay identification of a protein toxoid (denatured toxin) aerosol release. 


\section{Materials and methods}

\subsection{The Autonomous Pathogen Detection System}

Figure 1 shows the process flow diagram for environmental monitoring with the APDS including PCR confirmation. Most of the time the system will operate in the left (green) column. A potential immunoassay positive will send the system to the second (yellow) loop, with a "Level 1" response depending on the agent and signal strength. This response represents both actions that may be taken by the instrument itself (e.g., paging experts with a request for data review) and by external systems (e.g., security cameras being checked). If the agent contains DNA, then PCR confirmation is initiated. If this is positive, then a more extensive "Level 2" response is initiated.

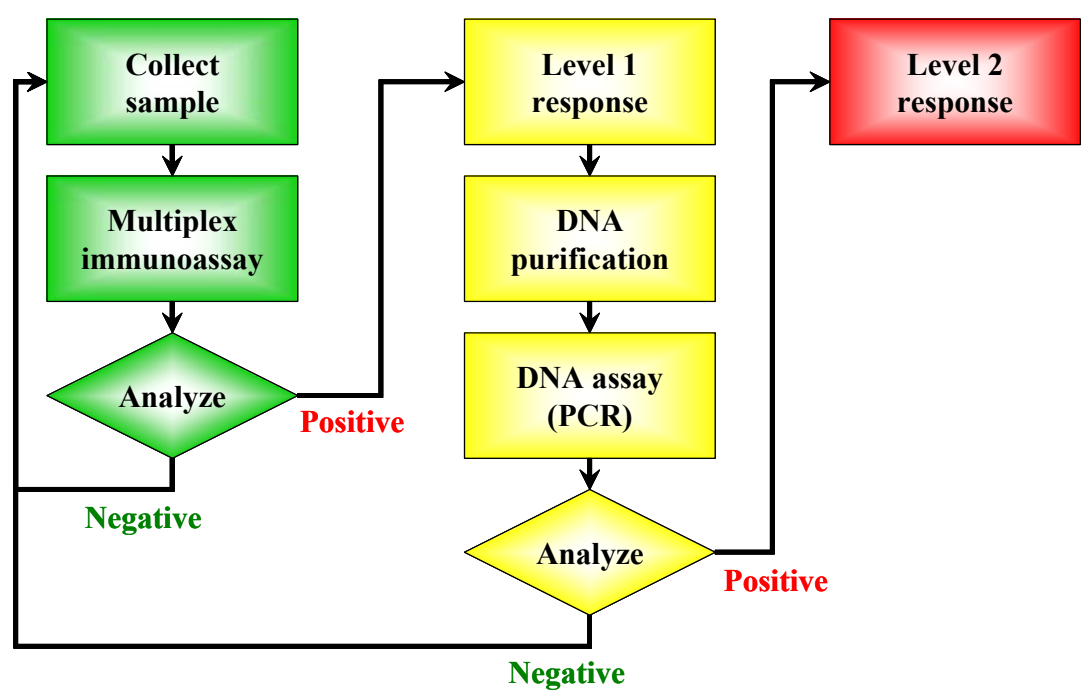

Figure 1: Process flow diagram of environmental monitoring with the current APDS including PCR confirmation.

The goal of having two independent, autonomous, but still "gold-standard" assays is to provide highest confidence in detection results in the shortest possible period of time. This will allow decisive responses ("Level 2" in Figure 1) to begin before samples could even be transferred to a traditional, manual laboratory to perform similar assays.

The APDS with multiplex immunoassay capabilities (the left, green column of Figure 1) are described in a recent publication (McBride, Masquelier, et al., 2003). The aerosol collector (LLNL and Research International, Monroe WA) operates at up to 3,000 liters of air per minute and collects particles into $4 \mathrm{~mL}$ of water. The collection period is typically 59 minutes followed by one minute pumping the sample to the fluidics system before collection starts again. The fluidics system (Global FIA, Gig Harbor WA) performs a multi-step, bead-based immunoassay on a 100- $\mu \mathrm{L}$ sample using a flow cytometer (Luminex, Austin TX). This type of assay was described in some detail by McBride, Gammon, et al. (2003). The assay used in the present study is the most extensive panel run on the APDS to date: it tests for 11 agents and includes 4 controls to verify proper system performance. The agents include Bacillus anthracis $(B a)$, Yersinia pestis $(Y p)$, and Botulinum toxin (BoTox), with Bacillus globigii $(B g)$ and MS2 as simulants. Good 
sensitivity is achieved by using a 40-minute assay, though this time can be shortened. Immunoassay sensitivity varies significantly with pathogen, but with good antibodies the immunoassay can detect $1,000 \mathrm{cfu}$ which is $10,000 \mathrm{cfu} /(\mathrm{mL}$ sample) which is $40,000 \mathrm{cfu}$ collected at 3,000 (L air)/min.

In addition to extensive laboratory testing, the APDS with multiplex immunoassays was tested with live agents at Dugway Proving Grounds in September 2002 (McBride, Masquelier, et al., 2003). These tests proved that the end-to-end system can detect aerosolized, lethal bioagents. To show that the system can perform well in the environments of interest, two units were operated for four days in the Albuquerque airport in December 2002 and one unit was operated for seven days in the Washington DC subway in June 2003 (Figure 2). The systems performed well and showed no false positives in a total of 355 samples.
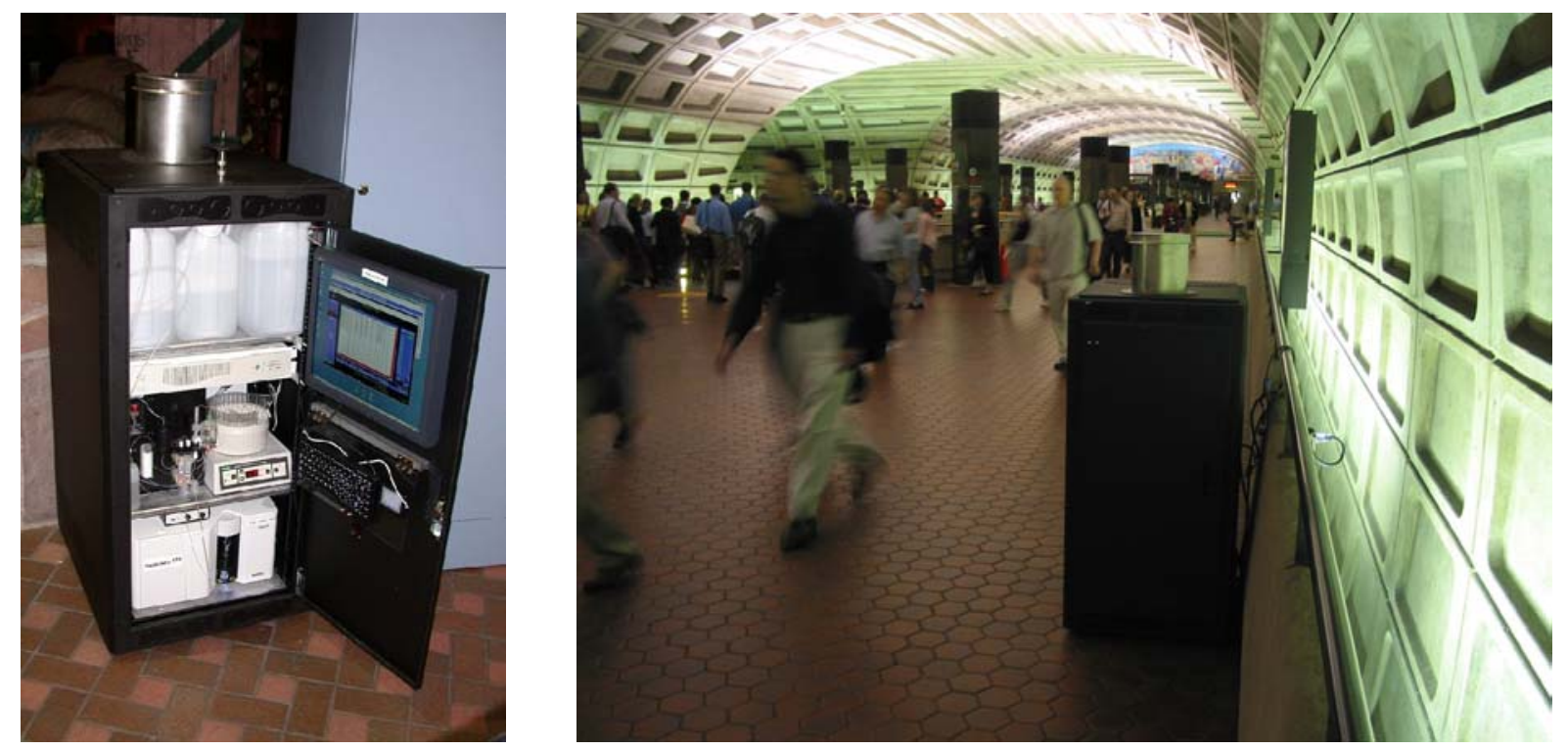

Figure 2: The APDS in short field tests in the Albuquerque airport (left panel) and Washington DC subway (right panel).

R\&D work this year added the capability to run PCR to detect DNA, confirming immunoassay positives (the center, yellow column of Figure 1). The flow-through PCR module used in the present testing was described by Belgrader, Elkin, et al. (2003). The DNA sequence signatures used in this testing were developed and extensively tested by LLNL for the Biological Aerosol Sentry and Information System (BASIS). The fluidic system and autonomous processes for the flow-through PCR module were developed as part of this year's APDS work. The current process uses $5 \mathrm{uL}$ of sample in a $25-\mu \mathrm{L}$ reaction. PCR can detect around 5 copies which is $1,000 \mathrm{cfu} /(\mathrm{mL}$ sample) which is 4,000 cfu collected at 3,000 (L air)/min. "Fast" and "slow" thermal cycling protocols were used in these tests. The fast protocol was 40 cycles of $95^{\circ} \mathrm{C}$ for $15 \mathrm{~s}$ and $60^{\circ} \mathrm{C}$ for $15 \mathrm{~s}$; the slow protocol was 40 cycles of $95^{\circ} \mathrm{C}$ for $15 \mathrm{~s}, 60{ }^{\circ} \mathrm{C}$ for $30 \mathrm{~s}$, and $72{ }^{\circ} \mathrm{C}$ for $15 \mathrm{~s}$. In some cases the slower protocol gave stronger PCR signals.

Since environmental samples can contain impurities that inhibit PCR and prevent reliable answers, a purification step by solid-phase extraction of DNA was integrated into the APDS this 
year. This extraction uses a microfluidic chip fabricated at LLNL which has been described by Belgrader, Ness, et al. 2002. This chip contains a bed of $\sim 20 \mu \mathrm{m} \times 100 \mu \mathrm{m}$ silica pillars and is often referred to as the "pillar chip." The autonomous processes were developed as part of this year's APDS work. The sample is mixed with guanidine at acidic $\mathrm{pH}$ before passing through the pillar chip, which causes the DNA to preferentially adsorb onto the silica surface. The chip is washed with ethanol and dried, then the DNA is desorbed and eluted into basic PCR buffer. This mixes with the PCR master mix before entering the PCR chamber. DNA purification is not needed with the clean air in the ASEC, but the APDS was run with and without the pillar chip to demonstrate that the DNA extraction was reliable.

Two complete APDS units were shipped to Dugway. One system was designated as the primary test unit and the secondary system was available for backup, but there were no failures of the primary system.

\subsection{Aerosol chamber}

The interior dimensions of the ASEC are $5 \mathrm{~m} \times 5 \mathrm{~m} \times 3 \mathrm{~m}$. The ASEC was equipped with a Babbington aerosol generator (referred to here as the nebulizer) capable of delivering aerosolized samples at variable flow rates $(0.2$ to $5 \mathrm{~mL} / \mathrm{min})$, mixed with chamber air at a with a turnover rate of 50 to $500 \mathrm{cfm}$, sustained over about 50 minutes. The chamber has a bank of 8 fans to continuously mix the air to maintain uniform concentration throughout. The APDS aerosol collector module was removed from the APDS chassis and positioned in the middle of the chamber (Figure 3); the chassis containing all other APDS components was set up outside the chamber. Consequently, only the aerosol collector was directly exposed to bioaerosols; the other modules processed antigen-containing samples that are liquid samples. Configuring the components in this manner minimized unnecessary exposure of equipment to bioaerosols and minimized the decontamination of the equipment required upon completion of the tests. Fluid lines and serial cables were established between the aerosol collector inside the chamber and the equipment outside the chamber via a sealed port.

Standard bioaerosol references were employed to monitor the dissemination. An aerodynamic particle sizer (APS) was positioned with its inlet tubing inside the chamber at an airflow rate of $1 \mathrm{~L} / \mathrm{min}$ for real-time measurements of particles in the 0.5 to 30 um size range. Pre-trial background levels of particles were measured using the APS with and without the operation of the APDS, and the baseline level of particles was measured after placing the nebulizer in the chamber, prior to dissemination. All-glass impinger air samplers (AGI-30s) were operated in the chamber. Each AGI was supplied with $20 \mathrm{ml}$ of $0.01 \mathrm{M}$ phosphate buffer and operated at an airflow rate of $12.5 \mathrm{~L} / \mathrm{min}$. 10 AGI-30 samplers were operated individually for 5-minute intervals, spanning the entire 50 minutes of release time. Six New Brunswick Slit-to-Agar Biological Samplers were positioned inside the chamber for sampling of $B g$, the only live simulant to released. The slit samplers were each operated for two minutes at six minute intervals. 

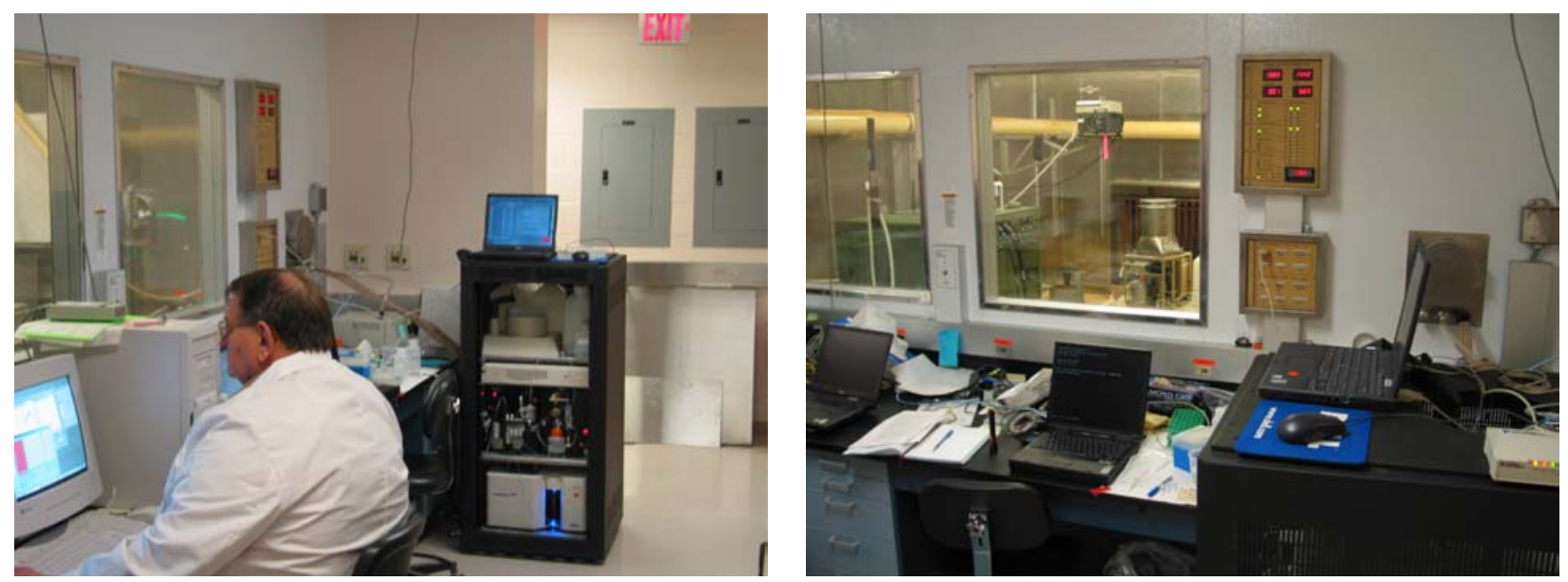

Figure 3: Photographs of the APDS at the ASEC; most of the system was outside of the camber in the control area (left panel), but the aerosol collector was inside the chamber on a table (visible through the window at the center of the right panel).

\subsection{Antigens}

Certified killed (gamma-irradiated) Bacillus anthracis $(\mathrm{Ba})$ Ames strain spores, certified killed (gamma-irradiated) Yersinia pestis (Yp) India 195/p strain vegetative cells, and Bacillus globigii $(B g)$ spores were provided by DPG Life Sciences support staff. Botulinum toxin A toxoid (BoTox) was purchased from Tetracore, Inc.

\subsection{Assay reagents}

Stock immunoassay reagents were prepared in bulk to ensure that reagents from the same lots were used for all testing, including the preliminary system characterization conducted at LLNL, the Dugway testing, and post-Dugway systems testing conducted at LLNL. Bulk reagents (bead mix, biotinylated antibody cocktail, reporter) were prepared at $10 \mathrm{X}$ concentrations and diluted just prior to use. All immunoassays were conducted using a mixture of 15 different bead classes. The bead set consisted of 11 classes of beads designed to screen for bioagents or simulants and 4 bead classes that served as assay controls. The negative control comprised a bead class coated with bovine serum albumin (BSA). Antigens will not bind specifically to BSA; consequently, the median fluorescent intensities (MFI) of the negative control should always be low. High MFIs on the negative control channel are a measure of non-specific binding. A bead coated with R-phycoerythrin served as an instrument control. A constant MFI value should be observed for this bead class; changes in MFI values indicate fluctuations in the Luminex optical performance. A bead class coated with biotinylated BSA was used as the fluorescent control; these beads bind the fluorescent reporter, streptavidin-phycoerythrin (SA-PE), and confirm the addition of reporter to the reaction mixture. Chicken IgG was used as antibody control with biotinylatedrabbit-anti-chicken-IgG as the corresponding detector. Signals are obtained only when fluidics, antibody cocktail, SA-PE, and the optical systems are all functioning properly.

PCR reagents nominally consisted of MasterMix (PCR buffer, MgCl2, dNTPs, primers, TaqMan probes, and Platinum Taq DNA polymerase), internal control DNA, and sample. The 3' end of the FRET probes for the multiplex Taqman assay were quenched by the Black Hole Quencher; 
the 5 ' fluorophores were FAM for the agent and TAMRA for the internal control. This gives the possibility of doing duplex real-time PCR in a two-color system. However, we found that since there is only one excitation source $(488 \mathrm{~nm})$ in the current APDS PCR module, the internal control fluorophore is too weakly excited. The internal control was not used and will be incorporated after a second excitation source is added.

\subsection{Bench-top QC and verification assays}

Immunoassays: Serial dilutions for each antigen preparation were prepared in ultrapure water at concentrations ranging from $1 \times 10^{2}$ to $5 \times 10^{8} \mathrm{cfu} / \mathrm{mL}$ or 0 to $10 \mu \mathrm{g} / \mathrm{mL}$ depending on the antigen, and samples were analyzed in triplicate on a bench-top Luminex system to produce calibration curves. Assays were conducted in 96-well filtration plates, pore size $1.2 \mu \mathrm{m}$. $50 \mu \mathrm{L}$ of the bead solution was mixed with $100 \mu \mathrm{L}$ sample and incubated 20 minutes at ambient temperature. The mixture was vacuum-aspirated, washed twice with $100 \mu l$ buffer to remove unbound antigen, and resuspended in $100 \mu \mathrm{L}$ PBS-TBN. $50 \mu \mathrm{L}$ of the biotinylated antibody solution was added to the bead mixture, and incubated 15 minutes. The mixture was vacuumaspirated, washed to remove excess detector antibody, and resuspended in $100 \mu \mathrm{L}$ PBS-TBN. $50 \mu \mathrm{L}$ SA-PE was added and the reaction mixture incubated 5 minutes. The mixture was vacuum-aspirated, washed, and resuspended in $100 \mu \mathrm{L}$ PBS-TBN. Samples were analyzed in the LX-100 flow analyzer. Data were acquired for 60 seconds.

Before every release, a portion of the antigen solution to be disseminated was analyzed to ensure that reagents were performing as expected. After each dissemination, an aliquot of the antigen solution remaining in the nebulizer was analyzed and compared to the pre-release sample to determine if the antigen was modified during dissemination. In addition, post-dissemination bench-top analysis was conducted on the sample collected by the APDS, the 10 AGI fractions, and samples obtained from APDS following aerosol collector decontamination.

PCR: Duplex PCR reactions were conducted using the same samples prepared for immunoassays to establish calibration curves using a Cepheid SmartCycler. The reactions were comprised of $15 \mu \mathrm{L}$ of MasterMix, $5 \mu \mathrm{L}$ of water, and $5 \mu \mathrm{L}$ of sample. Serial dilutions of antigens were performed, and each calibration curve incorporated both positive controls (added genomic DNA), and negative controls (water-only blanks).

Similar to the bench-top immunoassays, a portion of the antigen preparation to be disseminated was analyzed before every release to ensure that reagents were performing as expected. Postdissemination analysis was conducted on samples taken from the nebulizer, the 10 AGIs, the APDS sample, and aerosol collector decontamination samples.

\subsection{Aerosolization of antigens}

For each dissemination, $100 \mathrm{~mL}$ of antigen slurry was prepared in water; $98 \mathrm{~mL}$ was loaded into the nebulizer and $2 \mathrm{~mL}$ was held in reserve for pre-release bench-top testing. For each trial, the release was sustained for about an hour to coincide with the aerosol collection period. For each release, a target APS count was selected, and the nebulizer's peristaltic pump was cycled on and off to maintain the target reading. The dissemination was stopped after the APDS pumped the aerosol collector fluid out of the ASEC to the its fluidics module. 


\subsection{Decontamination}

After the dissemination, the chamber was purged continuously with clean air. When the APS indicated that particle counts inside the chamber had returned to baseline, the chamber was entered and the nebulizer, AGIs, and slit samplers (when used) were removed from the chamber.

After the chamber floor was mopped with bleach, the aerosol collector was manually cleaned using a series of surfactant and bleach rinses, followed by water flushes. The collector stack and virtual impactor were replaced with clean hardware, and the contaminated components were cleaned later in a sink. The final water rinse run through the reassembled collector was tested on the bench using PCR to certify it was clean.

\subsection{Timetable}

A timetable representing a typical experimental day is shown in Table 1. In general, the APDS was restarted at the end of the day and sampled the air in the chamber continuously, posting an immunoassay result every hour. When LLNL personnel arrived in the morning, the antigen solution was prepared and loaded into the nebulizer. Before opening the chamber to install the nebulizer, the APDS aerosol collector was turned off so that if any agent was stirred up by the action of entering the chamber, the perturbed particles would not be collected by the APDS. While the chamber was readied, bench-top analysis (immunoassay and PCR) of the pre-release antigen stocks was conducted.

The APDS collected for an hour during the release and posted the immunoassay results 45 minutes later. The APDS's signal analysis is nearly instantaneous. If positive, confirmatory PCR analysis was triggered. The time to reach a PCR positive varied between 15 and 60 minutes, depending on the agent concentration, the thermal cycling protocol, and whether DNA extraction was used.

Table 1: System test timetable.

\begin{aligned} & \hline Approximate time Action \\ & \hline (prev. day) 16:00 Restart system, run hourly sampling overnight. \\ & 08:30 Load aerosol generator, test nebulizer stock liquid. \\ & 09:00 Begin release, QC PCR reagents. \\ & 10:00 End aerosol collection. \\ & 10:45 Immunoassay result. \\ & 11:45 PCR result (if applicable). \\ & 12:15 Stop system, purge aerosol chamber. \\ & 13:00 Mop chamber, decon. APDS, decon. aerosol collector, \\ & begin bulk of bench-top assays (decon. liquid, pre- \\ & release and release samples, QC immunoassay \\ & reagents). \\ & 14:00 Make adjustments or run fluidics spikes if desired. \\ & 15:00 Decon. APDS fluidics if spiked. \\ & 16:00 Restart system, run hourly sampling overnight. \\ & \hline\end{aligned}




\section{Results and discussion}

\subsection{Summary of releases}

The test plan called for conducting a least one release each of Bacillus anthracis $(\mathrm{Ba})$ spores, Yersinia pestis ( $Y p$ ) vegetative cells, Bacillus globigii $(B g)$ spores, and botulinum toxin A toxoid (BoTox). A full test point consisted of collecting the disseminated bioaerosol, preparing and reading the multiplexed immunoassay, identifying immunoassay positives with a signal processing algorithm, extracting DNA, running real-time, flow-through PCR, and observing a cycle threshold, all in an unattended, continuous mode of operation (see Figure 1, previous). PCR assays were not conducted for the toxoid releases, since there is no guarantee of DNA in such samples. Table 2 summarizes all aerosolization trials conducted during ASEC testing.

An initial aerosolization release using water was run first to establish the flow rates of both the nebulizer and the air-handling system inside the ASEC and to check the response of the APS.

A total of 12 agent trials were conducted over 14 days of testing, for a total of four work weeks at Dugway. Live $B g$ was used in early releases so culturing with slit sampler plates could be performed. The first round of agent releases were done without DNA extraction to make sure the rest of the system performed properly.

Positive immunoassay responses could be observed for all 12 agent releases. However, in Trial 7, high background $B g$ signals from contamination prevented automatic identification; this is a Dugway-specific issue and doesn't reflect on the instrument performance. In Trial 10 the nebulizer slurry was mis-diluted to $1 / 10$ the planned concentration, and the resulting signal was below the threshold set for the test. The fact that the positive was easily identified manually means that more work is needed to tune the automatic triggering algorithm. This is discussed later.

Usually the PCR signals were strong. When there were problems with weak signals in the middle releases (Trials 4 and 6), we switched to the slower cycling protocol which was more robust. We have observed in the laboratory that some assays or samples require this less aggressive protocol. This is now the default protocol. 
Table 2: Summary of release and detection results.

\begin{tabular}{llllll}
\hline Trial & Date & Agent & Immuno. & PCR & Comments \\
\hline & $3 \mathrm{Sep}$ & water & - & Not run. & Blank release. \\
1 & $9 \mathrm{Sep}$ & $\mathrm{Bg}$ & + & + & Not an autonomous run. \\
2 & $10 \mathrm{Sep}$ & $\mathrm{Bg}$ & + & + & Run without DNA extraction. \\
3 & $11 \mathrm{Sep}$ & $\mathrm{Ba}$ & + & + & Run without DNA extraction. \\
4 & $15 \mathrm{Sep}$ & $\mathrm{Yp}$ & + & + & Run without DNA extraction; weak PCR. \\
5 & $16 \mathrm{Sep}$ & $\mathrm{Toxoid}$ & + & Not applicable. & \\
6 & $17 \mathrm{Sep}$ & $\mathrm{Ba}$ & + & + & Weak PCR; switched to slower PCR cycling. \\
7 & $18 \mathrm{Sep}$ & $\mathrm{Ba}$ & + & + & Bg contamination required forced PCR. \\
8 & $19 \mathrm{Sep}$ & $\mathrm{Ba}$ & + & + & \\
9 & $22 \mathrm{Sep}$ & $\mathrm{Ba}$ & + & + & \\
10 & $23 \mathrm{Sep}$ & $\mathrm{Yp}$ & + & Not run. & Below auto. PCR trigger. \\
11 & $23 \mathrm{Sep}$ & $\mathrm{Yp}$ & + & + & \\
12 & $24 \mathrm{Sep}$ & Toxoid & + & Not applicable. & \\
\hline
\end{tabular}

\subsection{Bacillus anthracis $(\mathrm{Ba})$ releases}

We report Bacillus anthracis $(B a)$ results first because this is the most important threat agent. A total of four $B a$ trials were conducted. The first release (Trial 3) was performed without using the DNA extraction (pillar chip) capability; results are shown in Figure 4. The left panel shows the result of the multiplexed immunoassay, with median fluorescent intensities (MFI) of the 11 agents and the negative control plotted versus time since restart. The MFI values for each bead class are steady after the initial equilibration until the spike in the $B a$ signal in response to the aerosolization of $B a$ spores. Note that responses on each of the other bead classes remains unchanged in the presence of a high concentration of $B a$; this indicates that the multiplexed assays are highly specific.

The right panel of Figure 4 shows the fluorescent signal versus thermal cycle. There is a clear PCR confirmation of the immunoassay positive. 

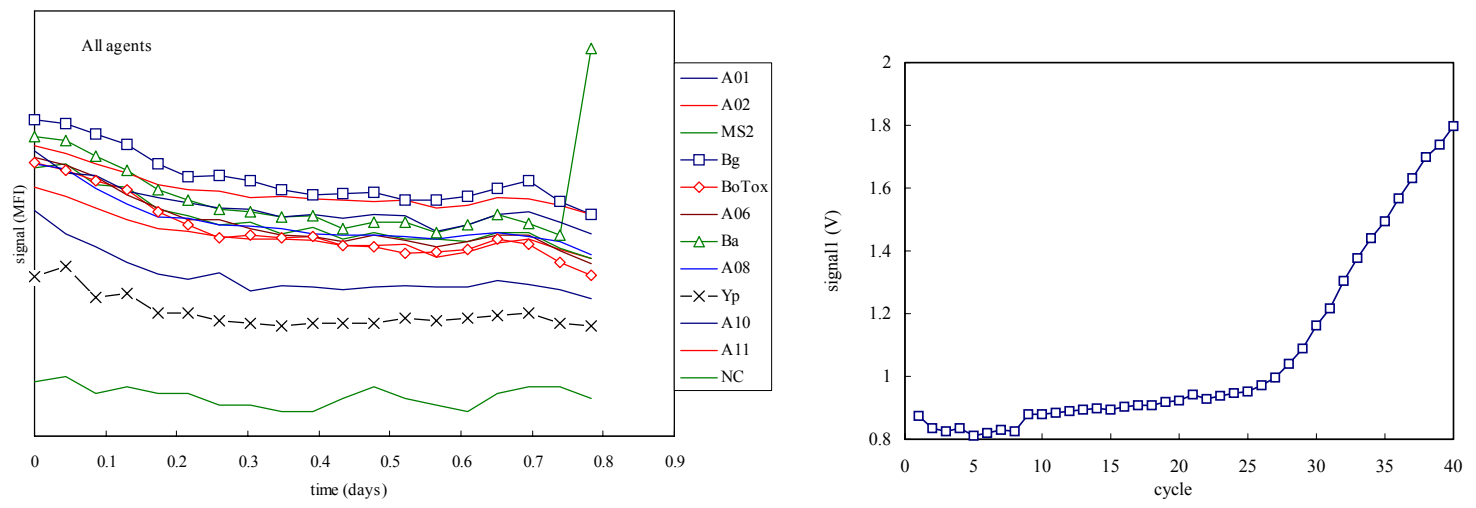

Figure 4: Results of Trial 3 showing detection and identification of a $\mathrm{Ba}$ release using a multiplex immunoassay (left panel) followed by strong PCR confirmation (right panel), as described in the text.

Weak PCR was observed for $B a$ Trial 6, which used a different PCR module. This prompted a change to a slower, more robust 3-temperature cycling protocol as noted earlier in Section 2.1. (There were also some PCR problems resulting from errors in reagent preparation.) Figure 5 shows the results from Trial 9, which included DNA extraction. This is the full demonstration of the APDS's new capability.
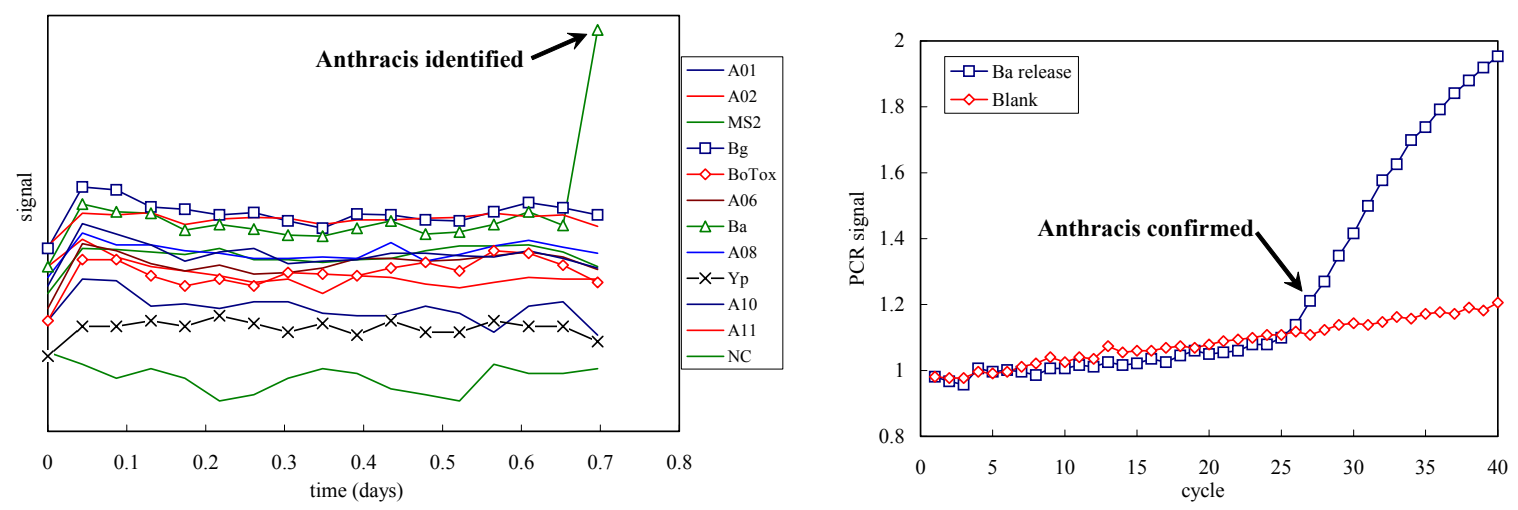

Figure 5: Results of Trial 9 showing detection and identification of a $B a$ release using a multiplex immunoassay (left) followed by DNA purification and strong PCR confirmation (right), with a negative sample (blank) for reference.

\subsection{Yersinia pestis $(Y p)$ releases}

Three releases were conducted with Yersinia pestis $(Y p)$. The first release (Trial 4) was performed without using the DNA extraction, and a weak PCR signal was observed (Figure 6). The required change in slope at about 30 cycles is seen, but the signal is really not convincing like Figure 5. 
For the next Yp release, pillar chip DNA extraction was implemented, and the 3-step PCR protocol was selected. The antigen solution disseminated during Trial 10 was not prepared correctly (the solution was too dilute by an order of magnitude) and although a positive immunoassay response was observed, the signals were below that required to automatically trigger PCR. A second antigen solution was prepared at the correct concentration and disseminated immediately (Trial 11) after the first, without disrupting the reporting cycle of the APDS. The results of Trial 10 and 11 are shown in Figure 7. Even the low release (second to last $Y p$ point) is clearly visible on the immunoassay signals, so there needs to be further work on optimizing the PCR triggering parameters.
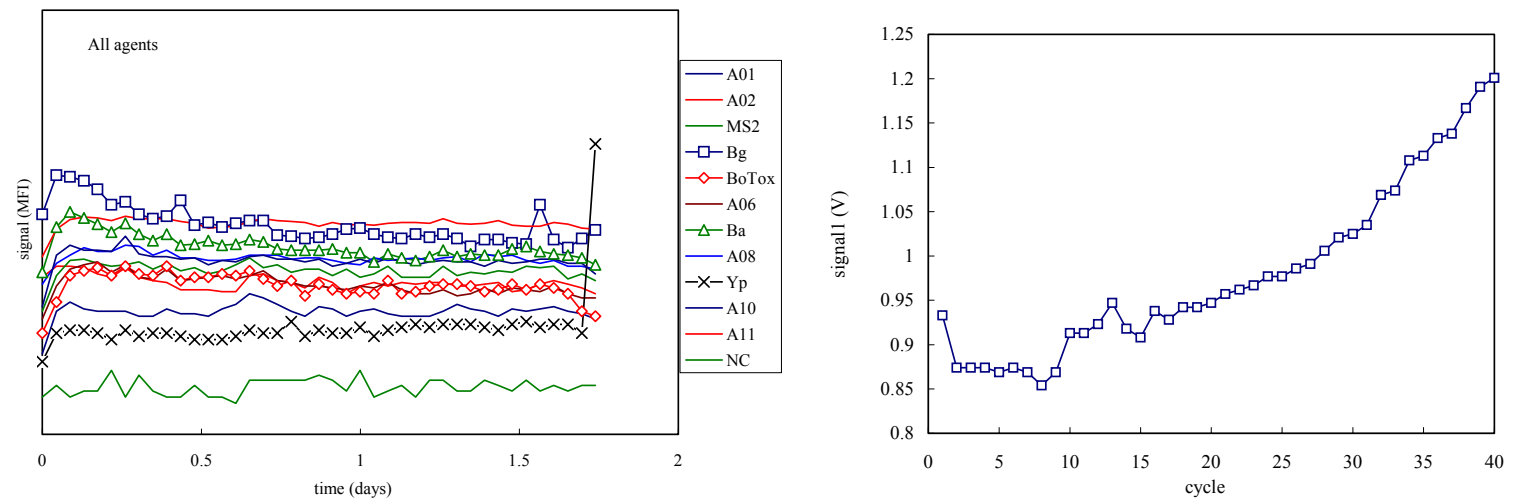

Figure 6: Results of Trial 4 showing multiplexed immunoassay detection and identification of a $Y p$ release (left), followed by weak PCR confirmation (right). After this experiment the PCR thermal protocol was changed and better results were obtained (Figure 7).
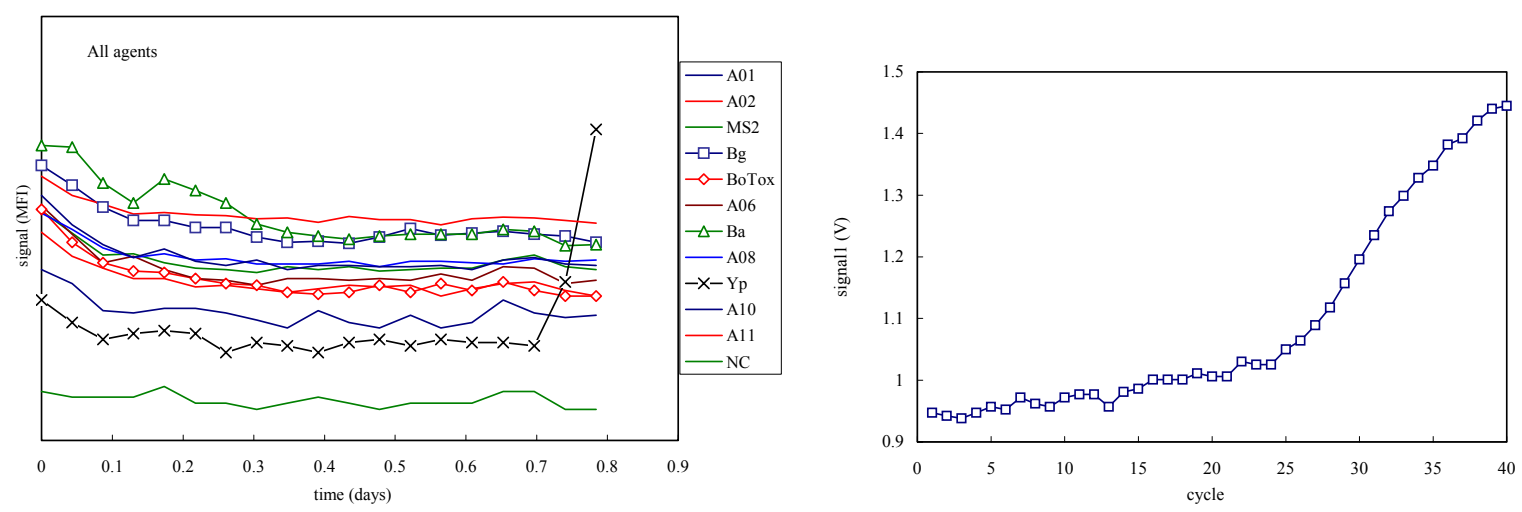

Figure 7: Results of Trial 10 and 11 showing detection and identification of a $Y p$ release using a multiplex immunoassay (left panel) followed by strong PCR confirmation (right panel). 


\subsection{Bacillus globigii $(\mathrm{Bg})$ releases}

Unlike the $B a$ and $Y p$ released in these trials, the $B g$ spores were viable and we were able to use slit samplers that collect particles onto culture plates. These plates were then incubated and colonies were counted to estimate the colony-forming-units (cfu) that were in the air. Figure 8 show the results of the first release with the APDS running in its new configuration (Trial 2), with clear detection of the release and identification of the agent. The average agent-containingparticles-per-liter-of-air (ACPLA) value reported for the slit samplers during this release was 49 .
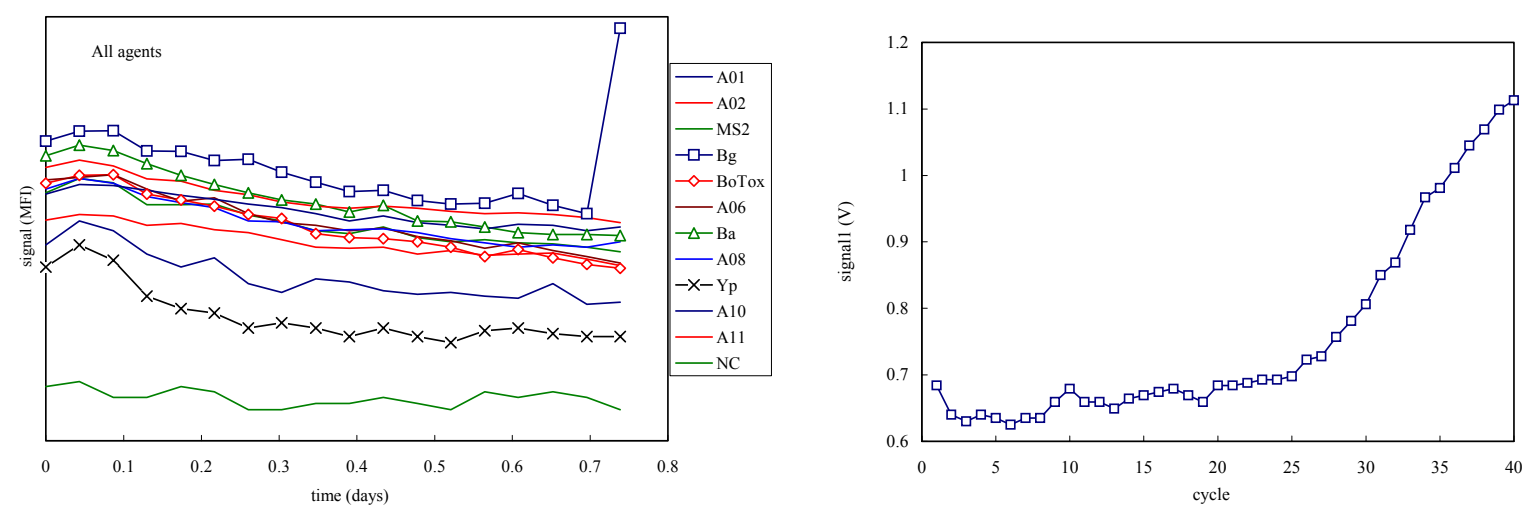

Figure 8: Results of Trial 2 showing detection and identification of a $B g$ release using a multiplex immunoassay (left panel) followed by strong PCR confirmation (right panel).

\subsection{Toxoid}

Two releases of botulinum A toxoid (formalin-treated botulinum A toxin) were performed. The result from Trial 12 is shown in Figure 9; note that only immunoassay testing was conducted, since protein toxins generally lack DNA. 


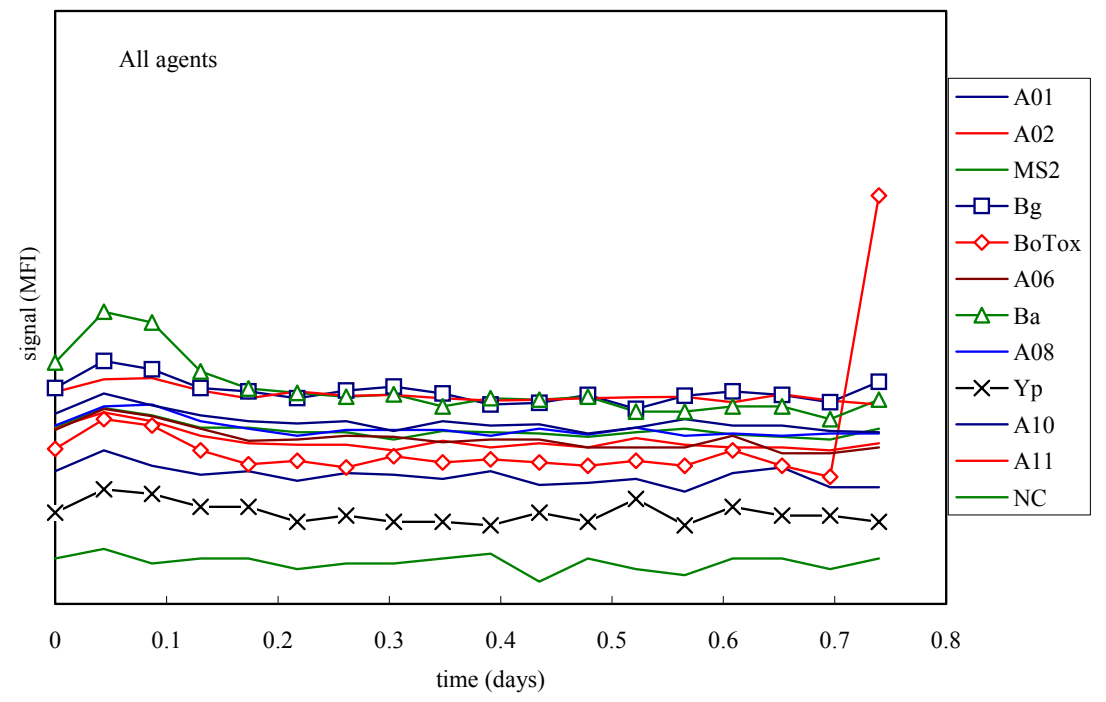

Figure 9: Immunoassay results following aerosolization of botulinum toxoid. 


\section{Conclusions}

The primary objective of the Dugway testing was to demonstrate the APDS with immunoassay identification and PCR confirmation of bacteria. A secondary objective was to demonstrate immunoassay identification of a protein toxoid aerosol release. Both objectives were achieved with multiple releases and clear identifications. The APDS was shown to be effective for identifying aerosolized Bacillus anthracis (Section 3.2), Yersinia pestis (Section 3.3), Bacillus globigii (Section 3.4), and botulinum toxoid (Section 3.5).

There were two areas that need further work. First, we showed that in our PCR assay for Yersinia pestis, the slower of our two thermal protocols gave significantly better performance. There needs to be more effort determining the best protocols on the APDS for the different agent signatures used. Second, the automatic PCR triggering parameters need to be further optimized. Trial 10 was mistakenly low release and did not trigger PCR, but it is clearly positive (first release of Figure 7, page 16). This will require a great deal more environmental baseline data from field testing, which is the major thrust of our FY04 work. Both of these areas for improvement concern how to best operate the instrument; the current hardware itself performed very well.

As part of this work, we settled on an effective timetable for testing instruments such as the APDS (Table 1, page 12). In it the system runs overnight or over the weekend, demonstrating autonomy and establishing baselines, and the releases are performed in the morning. The laborintensive part of the testing is post-release decontamination of the chamber and the instrument so the system can reach a baseline before the next release. Some agent carry-over and some system startup variability were observed, but these settled out overnight. In one case reagent contamination prevented proper autonomous immunoassay identification. These are issues for chamber testing but not for operation of the instrument in real applications. 


\section{References}

Belgrader, P.; Elkin, C. J.; Brown, S. B.; Nasarabadi, S. N.; Milanovich, F. P.; Colston, B. W.; and Marshall, G. D. A Reusable Flow-Through Polymerase Chain Reaction Instrument for the Continuous Monitoring of Infectious Biological Agents, Anal. Chem. 2003, 75, 34463450 .

Belgrader, P.; Ness, K.; Pourahmadi, P.; Brounstein, K.; Northrup, M. A.; Long, G. In Micro Total Analysis Systems 2002; Van den Berg, A., et al., Eds. Kluwer Academic Publishers: Netherlands, 2002, 697-698.

McBride, M. T.; Gammon, S.; Pitesky, M.; O’Brien, T. W.; Smith, T.; Aldrich, J.; Langlois, R. G.; Colston, B. W.; and Venkateswaran, K.S. Multiplexed Liquid Arrays for Simultaneous Detection of Simulants of Biological Warfare Agents, Anal. Chem. 2003, 75, 1924-1930.

McBride, M. T.; Masquelier, D.; Hindson, B. J.; Makarewicz, A. J.; Brown, S.; Burris, K.; Metz, T.; Langlois, R. G.; Tsang, K. W.; Bryan, R.; Anderson, D. A.; Venkateswaran, K. S.; Milanovich, F. P.; and Colston, B. W. Autonomous Detection of Aerosolized Bacillus anthracis and Yersinia pestis, Anal. Chem. 2003, 75, 5293-5299. 